\title{
Realization of SVPWM Arithmetic Simulation Based on MATLAB
}

\author{
SHE Yan \\ Shunde Polytechnic, Foshan 528333, China \\ Shelley186@sohu.com
}

Key words: SVPWM; MATLAB; simulation

Abstract: The paper introduces the basic principle of voltage space vector pulse wide modulation (SVPWM), presents the detailed method of realizing SVPWM under MATLAB/SIMULINK environment, and finally gives the experimental simulation results.

\section{Introduction}

The simulation technique is a method for experimental study by computer based on the mathematical model, is a very effective tool for the analysis of complex systems. In a sense, numerical simulation can be comparable with the real system as long as constructing of a sufficiently accurate mathematical model. In the general computer simulation software of control system, Math Works's MATLAB SIMULINK is a very excellent simulation software. Only draw the control system diagram of required analysis and design on the graphics window, the model system can be linearized and simulated by the software itself.

\section{SIMULINK Implementation of SVPWM Algorithm}

SVPWM control technology starts from the angle of motor, focus on the circular magnetic field in motor with constant amplitude, i.e. sinusoidal magnetic flux. It is the ideal circular flux trajectory by the three-phase symmetrical sine wave voltage as the reference, uses the actual magnetic flux generated by three-phase inverter different switch mode to approximate the reference flux circle, the flux trajectory is obtained by the addition of voltage space vector control, so as to achieve higher energy. The three-phase inverter bridge circuit is designed according to certain rules to control transistor of the three bridge arm on-off, can output three-phase sinusoidal voltage by the DC voltage. Therefore, bridge arm's on-off state of the three-phase bridge circuit is eight. The definition of these 8 switches combined into 8 basic specific space vector, are labeled as V4 (100), V6 (110), V2 (010), V3 (011), V1 (001), V5 (101) and 2 zero vector V0 (000), V7 (111) shown in Figure 1. The first is specific, can form a regular hexagon, respectively in the theta $=\omega \mathrm{t}=0^{\circ}, 60^{\circ}$, $120^{\circ} \ldots$, and the 6 vector size is determined by the DC power supply voltage Ud and can

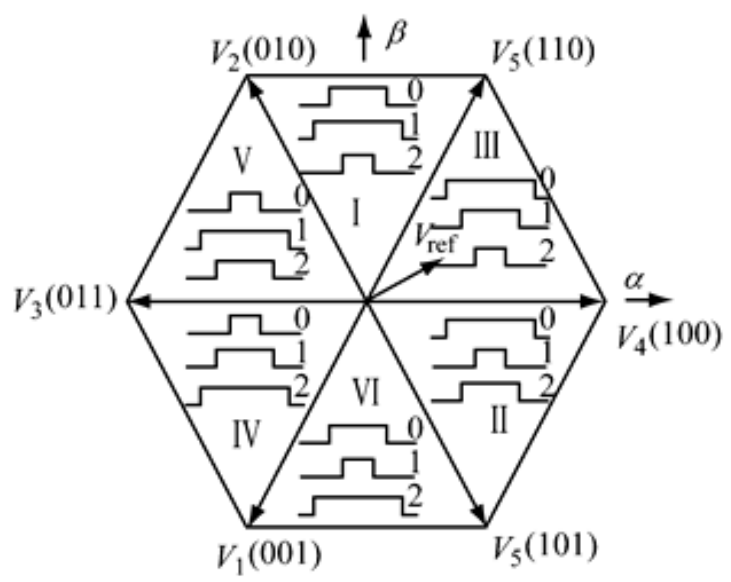

Fig. 1 SVPWM vector, sector and waveform not control, the $360^{\circ}$ area is divided into six 60 degree sector, but not directly obtain arbitrary phase angle and the vector $\mathrm{V}$ of the absolute value controlled. By using a linear combination of these 8 kinds of voltage vector can obtain more reference 
vector different from specific basic space vectors of phases, according to calculated relevant state time, control the switch turn-on and turn off[1][2]. Generally divided into four steps:

(1) Determine located region of the reference vector. (2) Calculate two adjacent switching voltage vector's action time. (3) Calculate a, b, c three-phase corresponding comparator switch point. (4) Produces the three-phase voltage Ua, Ub, Uc[3][4].

Determine the Vector Sector. The located sector of voltage vector is calculated by two dimensional static coordinate $\alpha_{\text {axis and }} \beta$ axis's component $u_{\alpha}$ and $u_{\beta}$ (the circle is divided into 6 sectors, sector number is indicated by $\mathrm{N})$. If ${ }^{u_{\beta}}>0$, then $\mathrm{A}=1$, or $\mathrm{A}=0$; if ${ }^{\sqrt{3}} u_{\alpha}-u_{\beta}>0$, then $\mathrm{B}=1$, or $\mathrm{B}=0$; if $-\sqrt{3} u_{\alpha}-u_{\beta}>0$, then $\mathrm{C}=1$, or $\mathrm{C}=0$. Sector $\mathrm{N}=\mathrm{A}+2 \mathrm{~B}+4 \mathrm{C}$. The sector model diagram is shown in Figure 2

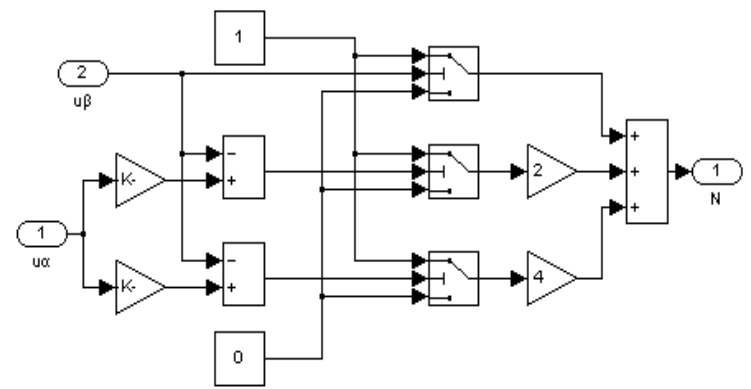

Fig. 2 sector model chart

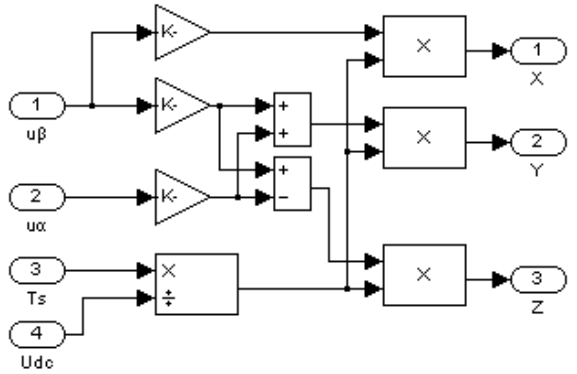

Fig.3: X, Y, Z model chart

\section{Calculate the Boundary Vector}

Time $^{T_{x}}, T_{y}$. Define $X=\sqrt{3} u_{\beta} \times T s / U d=\sqrt{3} \sin \theta \cdot T s \cdot u_{s} / U d$

$\left.Y=\frac{1}{2}\left(\sqrt{3} u_{\beta}+3 u_{\alpha}\right) \times T s / U d=\sqrt{3} \sin \theta+60^{\circ}\right) \cdot T s \cdot u_{s} / U d$

$Z=\frac{1}{2}\left(\sqrt{3} u_{\beta}-3 u_{\alpha}\right) \times T s / U d=\sqrt{3} \sin \left(\theta-60^{0}\right) \cdot T s \cdot u_{s} / U d$

$\mathrm{X}, \mathrm{Y}, \mathrm{Z}$, the model chart is shown in Figure 3..

According to different sectors of the voltage vector calculate 2 adjacent vector's action time Table 1 the boundary vector time assignment Table 2 three compare register assignment table in different sectors:

\begin{tabular}{c|c|c|c|c|c|c}
\hline $\mathrm{N}$ & 1 & 2 & 3 & 4 & 5 & 6 \\
\hline $\mathrm{Tx}$ & $\mathrm{Z}$ & $\mathrm{Y}$ & $-\mathrm{Z}$ & $-\mathrm{X}$ & $\mathrm{X}$ & $-\mathrm{Y}$ \\
\hline $\mathrm{Ty}$ & $\mathrm{Y}$ & $-\mathrm{X}$ & $\mathrm{X}$ & $\mathrm{Z}$ & $-\mathrm{Y}$ & $-\mathrm{Z}$ \\
\hline
\end{tabular}
table in different sectors:

\begin{tabular}{l|l|l|l|l|l|l}
\hline $\mathrm{N}$ & 1 & 2 & 3 & 4 & 5 & 6 \\
\hline $\mathrm{T} 1$ & $\mathrm{~Tb}$ & $\mathrm{Ta}$ & $\mathrm{Ta}$ & $\mathrm{Tc}$ & $\mathrm{Tc}$ & $\mathrm{Tb}$ \\
\hline $\mathrm{T} 2$ & $\mathrm{Ta}$ & $\mathrm{Tc}$ & $\mathrm{Tb}$ & $\mathrm{Tb}$ & $\mathrm{Ta}$ & $\mathrm{Tc}$ \\
\hline $\mathrm{T} 3$ & $\mathrm{Tc}$ & $\mathrm{Tb}$ & $\mathrm{Tc}$ & $\mathrm{Ta}$ & $\mathrm{Tb}$ & $\mathrm{Ta}$
\end{tabular}

$T_{x}, T_{y}$, the values as shown in the following 
table 1. The multiplexer can constitute a model graph. When $T_{x}+T_{y}>T_{s}$, $T_{x 1}=T_{x} \frac{T_{s}}{T_{x}+T_{y}} T_{y 2}=T_{y} \frac{T_{s}}{T_{x}+T_{y}}$.

Find out the 3 Vector Switching Points T1, T2, T3.

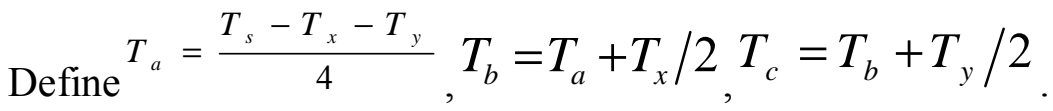

The model diagrams of $\mathrm{Ta}, \mathrm{Tb}$ and $\mathrm{Tc}$ are shown in Figure 4.

. The last step is to value the above three parameters in table 2 according to the different sectors. The multiplexer can constitute a model graph.

Generation of PWM Waveform and Realization of Inverter. SVPWM is using the equivalent time's triangular wave of constant frequency and amplitude to modulate 3 input time T1,T2,T3, the triangular wave compared with space vector switching point $\mathrm{Tx}$, once Tx and the triangular wave are equal, just change PWM wave state. Switch set determines period and amplitude of the triangle wave[5]. At the same time switching device in the abstract, the switch device of upper and lower bridge arm is equivalent to 1 ideal switch. The generation of the PWM waveform and the inverter model are shown in figure5.

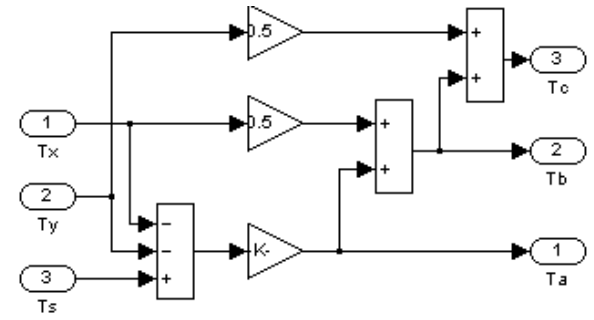

Fig.4 Ta, Tb, Tc model chart is calculated

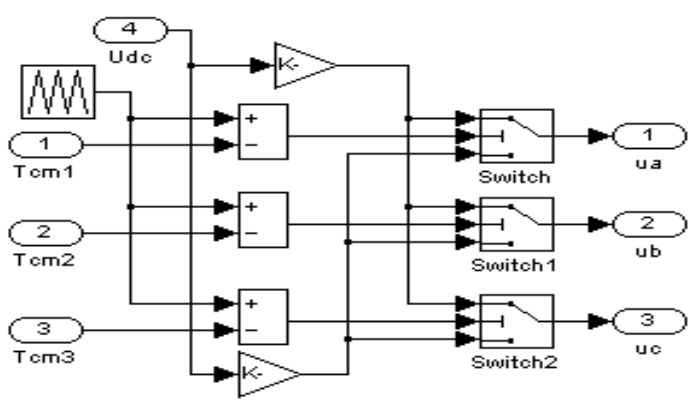

Fig.5 PWM generation and inverter model chart

\section{SVPWM Simulation Model and Results[6][7]}

Above each model diagram separately are packaged to connect, SVPWM simulation model is shown in Figure 6. Assume switching frequency is $2.4 \mathrm{KHz}$ when $f_{S}=50 \mathrm{~Hz}$, $\mathrm{Udc}=600 \mathrm{~V}$. After $10 \mathrm{~s}$ simulation, the simulation of $\mathrm{Ua}$ is obtained as shown in Figure 7.

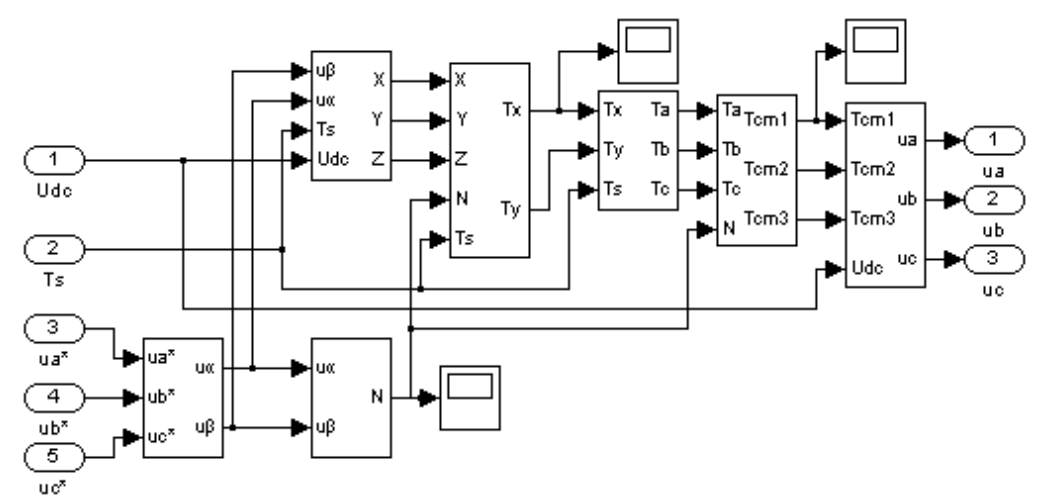

Fig. 6 SVPWM simulation model diagram 


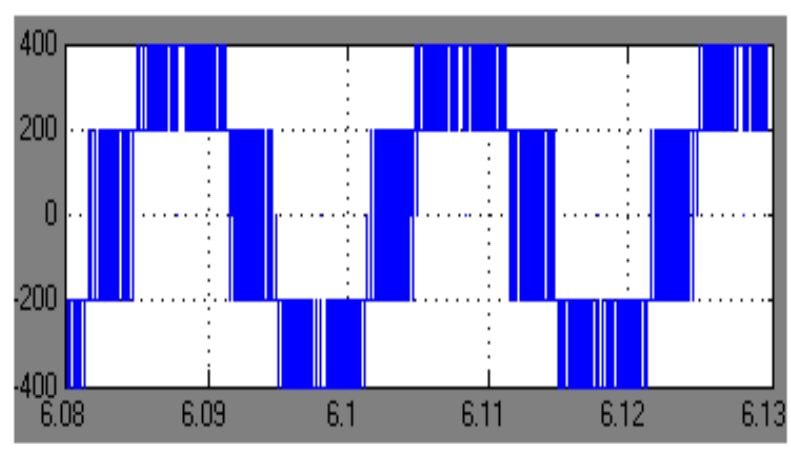

Fig.7 Ua simulation waveforms

\section{Conclusion}

Simulation is an important tool of product design. Using MATLAB SIMULINK is convenient for simulation, the model is intuitive without the need of programming, easy to understand and use. The simulation results show, the output voltage waveform and current is sinusoidal, that validate the space vector modulation. The control algorithm can be used for digital signal processor, to realize the digital motor controlled, providing theoretical basis and necessary system parameters for further research and design of AC drive system.

\section{Reference}

[1] CHEN Jian. Power electronics[M] . Beijing: Higher Education Press,2002.

[2] PAN Xiaosheng, HAO Shiyou. 50 cases of MATLAB motor simulation essence[M]. Beijing: Electronics Industry Press,2007.8.

[3] WANG Chenyuan, LI Haodong, XIA Jiakuan. Study of Intelligent Vector Control System Based on TMS320F240[J]. Applied Power Electronics Conference and Exposition,2001,2 (5):550-553.

[4] ZHOU Yuanshen. AC\& DC Adjustable speed system and MATLAB simulation[M]. Beijing: Chinese Power Press, 2004.

[5] LI Yong, HUANG Lipei, LI Fahai, All Digital Space Vector PWM Induction Motor Drive Based on Flux Control[J]. IEEE TENCON,2003,3 ( 8):598-601.

[6] SHE Yan, LI Ling. Simulation of Variable Frequency System Based on SVPWM Vector Control [J].Electric Machines \& Control Application, 2009, 36 (7) : 63-66.

[7] GONG Yunfei, FU Lixin. Simulation of PMSM Vector Control System based on Matlab [J]. Micro motor, 2007, 40 (2):33-36. 